\title{
Gamma Prime Precipitate Evolution During Aging of a Model Nickel-Based Superalloy
}

\author{
A.J. GOODFELLOW, E.I. GALINDO-NAVA, K.A. CHRISTOFIDOU, N.G. JONES, \\ T. MARTIN, P.A.J. BAGOT, C.D. BOYER, M.C. HARDY, and H.J. STONE
}

The microstructural stability of nickel-based superalloys is critical for maintaining alloy performance during service in gas turbine engines. In this study, the precipitate evolution in a model polycrystalline Ni-based superalloy during aging to 1000 hours has been studied via transmission electron microscopy, atom probe tomography, and neutron diffraction. Variations in phase composition and precipitate morphology, size, and volume fraction were observed during aging, while the constrained lattice misfit remained constant at approximately zero. The experimental composition of the $\gamma$ matrix phase was consistent with thermodynamic equilibrium predictions, while significant differences were identified between the experimental and predicted results from the $\gamma^{\prime}$ phase. These results have implications for the evolution of mechanical properties in service and their prediction using modeling methods.

DOI: $10.1007 / \mathrm{s} 11661-017-4336-\mathrm{y}$

(C) The Author(s) 2017. This article is an open access publication

\section{INTRODUCTION}

POLYCRYSTALLINE Ni-based superalloys are the material of choice for many high-temperature structural applications in gas turbine engines. Their remarkable mechanical performance is derived from the presence of an ordered $\mathrm{L}_{2}$ (strukturbericht notation) $\gamma^{\prime}$ precipitate phase within the disordered A1 $\gamma$ matrix. The principal mechanisms by which these alloys are strengthened include order and coherency strengthening from the $\gamma^{\prime}$ precipitates, as well as solid solution strengthening of the $\gamma$ matrix phase and grain boundary hardening. ${ }^{[1]}$ As the extent of precipitation strengthening is dependent on the $\gamma^{\prime}$ morphology and particle size distribution, these are carefully controlled through sagacious selection of heat treatments. However, care is taken to ensure that the resultant microstructure delivers an appropriate balance of properties.

The precipitate size at which peak strength is obtained corresponds to the transition from weak to strong pair dislocation coupling and, as such, varies with alloy composition. For example, this occurs for 55 to $85 \mathrm{~nm} \gamma^{\prime}$

A.J. GOODFELLOW, E.I. GALINDO-NAVA, K.A. CHRISTOFIDOU, N.G. JONES, and H.J. STONE are with the Department of Materials Science and Metallurgy, University of Cambridge, 27 Charles Babbage Road, Cambridge CB3 0FS, UK. Contact e-mail: hjs1002@cam.ac.uk T. MARTIN and P.A.J. BAGOT are with the Department of Materials, University of Oxford, Parks Road, Oxford OX1 3PH, UK. C.D. BOYER is with the Canadian Neutron Beam Centre, Chalk River, ON K0J 1J0, Canada. M.C. HARDY is with the Rolls-Royce plc, PO Box 31, Derby DE24 8BJ, UK.

Manuscript submitted July 4, 2017.

Article published online October 10, 2017 precipitates in Nimonic 105, but just 26 to $30 \mathrm{~nm}$ for PE16. ${ }^{[2]}$ However, a unimodal distribution of such fine precipitates is difficult to achieve in practice and has been associated with reduced ductility ${ }^{[3]}$ and creep performance. $^{[4,5]}$ As such, a multimodal particle size distribution is often utilized, comprising secondary $(\sim 100$ to $250 \mathrm{~nm})$ and tertiary ( $\sim 5$ to $50 \mathrm{~nm})$ intragranular precipitates. Larger, primary $(\sim 1 \mu \mathrm{m})$ intergranular precipitates may also be present, depending upon the solution heat treatment temperature.

The evolution of $\gamma^{\prime}$ particle size distributions during high-temperature service will affect the mechanical properties and must therefore be understood. Computational tools based upon thermodynamic and kinetic models exist to predict such precipitate evolution. ${ }^{[6-9]}$ However, further experimental studies are needed to validate the assumptions made in these models, particularly the compositions of the $\gamma^{\prime}$ precipitates, as these are known to differ between the primary, secondary, and tertiary distributions and will change with time at temperature.

In this study, the $\gamma$ and $\gamma^{\prime}$ phase compositions and the distribution of the $\gamma^{\prime}$ precipitates have been investigated in a model superalloy as a function of time at temperature using a combination of transmission electron microscopy and atom probe tomography. The resulting effect on lattice misfit has also been studied using neutron diffraction. These data identify the key discrepancies between thermodynamically predicted and experimentally measured precipitate compositions, which may have significant implications for the modeling of precipitate evolution and alloy strength. 


\section{EXPERIMENTAL DETAILS}

To characterize the effect of aging on microstructure, a model Ni-based superalloy was designed, with nominal composition given in Table I. This composition lies within the range of current, high-strength polycrystalline Ni-based superalloys, such as RR1000, ${ }^{[10]}$ and is intended to have low lattice misfit between the $\gamma$ matrix and $\gamma^{\prime}$ precipitate phases at room temperature, comparable to certain commercial disk alloys. ${ }^{[1,12]}$ The alloy was manufactured through vacuum induction melting (VIM) using elements of $\geq 99.9$ pct. purity and cast into $10 \mathrm{~mm}$-diameter cylindrical bars using steel molds.

Differential Scanning Calorimetry (DSC) was carried out on the as-cast material using a NETZSCH 404 instrument. Samples were heated at $10 \mathrm{~K} \mathrm{~min}^{-1}$ to $1723 \mathrm{~K}$ $\left(1450{ }^{\circ} \mathrm{C}\right)$, before cooling at the same rate to room temperature. From the thermograms acquired, the $\gamma^{\prime}$ solvus and solidus temperatures were determined to be $1448 \mathrm{~K}$ and $1560 \mathrm{~K}\left(1175^{\circ} \mathrm{C}\right.$ and $\left.1287^{\circ} \mathrm{C}\right)$, respectively. This enabled a suitable homogenization heat treatment temperature to be identified within the single $\gamma$ phase field.

Homogenization of the alloy was conducted for 22 hours at $1523 \mathrm{~K}\left(1250{ }^{\circ} \mathrm{C}\right)$ in an Ar-backfilled quartz ampoule, to avoid oxidation. Subsequent air cooling occurred at an average rate of $\sim 7.8 \mathrm{~K} \mathrm{~s}^{-1}$ for the initial $200 \mathrm{~K}$, slowing to an average of $\sim 1.6 \mathrm{~K} \mathrm{~s}^{-1}$ between $1273 \mathrm{~K}$ and $673 \mathrm{~K}$ $\left(1000{ }^{\circ} \mathrm{C}\right.$ and $\left.400{ }^{\circ} \mathrm{C}\right)$. Sections of the homogenized alloy were subjected to aging heat treatments at $1033 \mathrm{~K}\left(760^{\circ} \mathrm{C}\right)$ for durations of 1, 2, 16, 100, 200, and 1000 hours, followed by air cooling at an average rate of $\sim 4.4 \mathrm{~K} \mathrm{~s}^{-1}$

Thermodynamic modeling to determine the equilibrium composition of the matrix and $\gamma^{\prime}$ precipitate phases at $1033 \mathrm{~K}\left(760{ }^{\circ} \mathrm{C}\right)$ was conducted using the ThermoCalc software package with the TCNi7 database, excluding all other phases. The lattice parameters of the $\gamma$ and $\gamma^{\prime}$ phases ( $a_{\gamma}$ and $a_{\gamma^{\prime}}$ respectively) were obtained from the predicted molar volumes $\left(V_{\mathrm{m}}\right)$ using Eq. [1], and the lattice misfit $(\delta)$ was then calculated from Eq. [2].

$$
\begin{gathered}
a=\left[\frac{4 V_{m}}{N_{A}}\right]^{1 / 3} \\
\delta=\frac{2\left(a_{\gamma^{\prime}}-a_{\gamma}\right)}{\left(a_{\gamma^{\prime}}+a_{\gamma}\right)}
\end{gathered}
$$

Electron transparent samples of the heat-treated alloy for microstructural analysis in a transmission electron microscope (TEM) were prepared by electropolishing and through the production of carbon replicas. Electropolishing was performed in a 5 pct. perchloric acid in methanol solution at a temperature of $268 \mathrm{~K}\left(-5^{\circ} \mathrm{C}\right)$ and a voltage of $20 \mathrm{~V}$.

Table I. Nominal Composition of the Alloy Investigated in This Study

\begin{tabular}{lllllr}
\hline Element & $\mathrm{Al}$ & $\mathrm{Ti}$ & $\mathrm{Cr}$ & $\mathrm{Mo}$ & $\mathrm{Ni}$ \\
\hline Content (at. pct) & 6 & 5 & 15 & 3 & bal. \\
\hline
\end{tabular}

Carbon replica samples were obtained by electrolytically etching material polished to a $0.5 \mu \mathrm{m}$ finish in a 10 pct. phosphoric acid in water solution at $\sim 3 \mathrm{~V}$ until a blue halo appeared. After washing in ethanol, formvar in chloroform solution was deposited on the sample surface and used to attach a piece of acetate sheet. Once dry, the acetate sheet was removed to eliminate any over-etched $\gamma^{\prime}$ particles from the surface. The samples were then sputter coated with carbon, and this carbon coating was scored into $\sim 2 \mathrm{~mm}$ squares. Finally, electrolytic etching in a 20 pct. perchloric acid in ethanol solution at $10 \mathrm{~V}$ was carried out until the carbon coat began to blister. These fragments were then floated onto copper TEM grids for analysis.

Microstructural imaging was carried out by Scanning Transmission Electron Microscopy (STEM) using an FEI Tecnai Osiris TEM, operated at an accelerating voltage of $200 \mathrm{keV}$. Compositional analyses were performed by Energy-Dispersive X-ray Spectroscopy (EDX) in the same instrument, using an FEI Super-X EDX detector.

The electropolished samples were used for compositional analysis of the $\gamma$ phase using STEM-EDX. Data were acquired from regions of these samples between the $\gamma^{\prime}$ precipitates. The same method could not reliably be used for the $\gamma^{\prime}$ precipitates, as it was not possible to ensure that the electron beam did not pass through $\gamma$ phase above or below the $\gamma^{\prime}$ precipitates. To address this, compositional analysis of the $\gamma^{\prime}$ precipitates was performed on the samples that were prepared as carbon extraction replicas, which were devoid of the $\gamma$ phase.

Particle size distributions (PSDs) for each heat treatment were determined by manually tracing around a minimum of 300 secondary $\gamma^{\prime}$ particles on images of the carbon replica samples. This approach was required due to the presence of overlapping particles, which cannot be separated automatically. Analysis of the precipitate outlines was performed using ImageJ,${ }^{[13]}$ from which the equivalent circular diameters were obtained. Tertiary $\gamma^{\prime}$ analysis was carried out via the same method but using higher resolution STEM micrographs. The equivalent circular diameters were binned using the Freedman-Diaconis method ${ }^{[14]}$ and fitted with lognormal functions, given in Eq. [3], using Igor Pro (WaveMetrics, Lake Oswego, OR). The average precipitate size after each heat treatment was taken as the median of the lognormal functions $\left(e^{u}\right)$ and the associated uncertainties were taken to be the width of the function away from the median value $\left(e^{(\mu+\sigma)}\right.$ and $\left.e^{(\mu-\sigma)}\right)$, where $\sigma$. is the error (standard deviation) associated with the coefficient given by the Igor Pro software.

$$
f(x)=\frac{1}{x w \sqrt{2 \pi}} \exp \left(-\left[\frac{(\ln (x)-\mu)^{2}}{2 w^{2}}\right]\right)
$$

To determine the volume fractions of the secondary $\gamma^{\prime}$ precipitates, Scanning Electron Microscopy (SEM) was performed using an FEI Nova NanoSEM FEG SEM operated at $\sim 5 \mathrm{keV}$. Samples in each heat-treated condition were polished to $0.06 \mu \mathrm{m}$ finish with colloidal silica and imaged in Backscattered Electron Imaging (BSE) mode. Quantification of the secondary $\gamma^{\prime}$ volume fraction was achieved using thresholded images in 
ImageJ. The uncertainty quoted with the volume fraction measurements was taken to be the standard deviation of the volume fraction in four separate areas across each sample.

Atom Probe Tomography (APT) was performed for compositional analysis of the constituent phases and comparison with the results obtained using STEMEDX. APT samples were prepared from needles with a square cross-section of length $0.5 \mathrm{~mm}$. Subsequent electropolishing was performed in two stages: firstly using a solution of 10 pet. perchloric acid in acetic acid at a voltage of $22 \mathrm{~V}$, and secondly using a solution of 2 pct. perchloric acid in 2-butoxyethanol at $23 \mathrm{~V}$. Data were acquired from each electropolished needle using a LEAP $5000 \mathrm{XR}$ instrument in laser mode with a wavelength of $355 \mathrm{~nm}$. APT data were acquired at $50 \mathrm{~K}\left(-223^{\circ} \mathrm{C}\right)$, a pulse rate of $200 \mathrm{kHz}$, and a pulse energy of $50 \mathrm{pJ}$.

Neutron diffraction was carried out on the C2 powder diffractometer at the Canadian Neutron Beam Centre (CNBC), Chalk River, Canada. The wavelength of the incident beam was determined to be $\sim 1.33 \AA$ using an $\mathrm{Al}_{2} \mathrm{O}_{3}$ standard. Data were acquired from each sample for 3 hours at room temperature, using a position-sensitive detector over a $2 \theta$ range of 36 to $116 \mathrm{deg}$. The samples were rotated during data collection to improve the counting statistics. For each sample, the $\gamma^{\prime}$ superlattice reflections were fitted individually in WaveMetrics Igor Pro using Gaussian functions. The associated lattice parameter was determined from the fitted superlattice positions using the Nelson-Riley method, in which the equivalent lattice parameters from each peak were plotted against the associated absorption error, $(\delta a / a)_{\mathrm{abs}}$, Eq. [4], and the lattice parameter was taken as the linear intercept. ${ }^{[15]}$ The positions of the $\gamma$ peaks were obtained by fitting the fundamental reflections with two Gaussian functions, one of which was constrained to the position associated with the previously determined $\gamma^{\prime}$ lattice parameter. As before, the $\gamma$ lattice parameter was obtained from the fitted peak positions using the Nelson-Riley function, Eq. [4]. Conversion of the measured lattice parameters to lattice misfit was performed using Eq. [2].

$$
(\delta a / a)_{\mathrm{abs}}=\frac{1}{2}\left(\frac{\cos ^{2} \theta}{\sin \theta}+\frac{\cos ^{2} \theta}{\theta}\right)
$$

\section{RESULTS}

STEM images of the $\gamma^{\prime}$ phase from the carbon replicas of the alloy in each heat treatment condition are shown in Figure 1. With the exception of the sample aged for 1000 hours, all conditions exhibited bimodal PSDs of secondary and tertiary $\gamma^{\prime}$. As a consequence of the different precipitate sizes, images of the secondary (Figure 1, left-hand side images) and tertiary $\gamma^{\prime}$ (Figure 1, right-hand side images) have been displayed at different magnifications.

The morphology of the secondary $\gamma^{\prime}$ showed no appreciable change with aging time up to 16 hours, with all secondary precipitates remaining approximately cuboidal. On further aging to 100 hours, octodendritic precipitates alongside smaller, cuboidal precipitates were observed, characteristic of the morphological instabilities associated with precipitate splitting. ${ }^{[6,17]}$ Following aging for 200 hours, only octodendritic precipitates were observed throughout the sample. After 1000 hours, the secondary $\gamma^{\prime}$ appeared finer and more spherical than those observed during shorter duration exposures. In contrast to the secondary $\gamma^{\prime}$, the tertiary $\gamma^{\prime}$ remained approximately spherical throughout aging and increased continuously in size up to 200 hours, after which they were no longer present within the microstructure.

PSDs of both the secondary and tertiary $\gamma^{\prime}$ obtained from analysis of the STEM images of the as-homogenized condition and following aging for 1, 16, 100, and 1000 hours are shown in Figure 2. All PSDs were well described by a lognormal function. The single additional peak visible between the distributions of secondary and tertiary $\gamma^{\prime}$ precipitates in the alloy after aging for 16 hours is due to the presence of one large tertiary precipitate and one small secondary precipitate, of similar intermediate size being identified in the microstructural regions examined. Example PSDs of the secondary and tertiary precipitates, alongside the fitted lognormal distributions, for the sample aged for 16 hours are provided in the Supplementary Information to demonstrate the quality of the fit to the data.

The median diameters of the secondary and tertiary $\gamma^{\prime}$ precipitates are presented in Figure 3. The median diameters of the secondary $\gamma^{\prime}$ remained approximately constant, $\sim 200 \mathrm{~nm}$, throughout aging, although the sample aged for 100 hours displayed a noticeably lower median value. This was also associated with a broader PSD, as indicated by the larger error bars quoted with this data point. This arose as a result of the presence of regions containing smaller, cuboidal precipitates alongside regions of larger, octodendritic precipitates in this sample. With increasing aging time, the size of the tertiary $\gamma^{\prime}$ increased monotonically, accompanied by a progressive increase in the width of the PSDs. Unlike the secondary $\gamma^{\prime}$, no changes associated with splitting instabilities were observed.

The volume fractions of secondary precipitates obtained from analysis of the BSE images are presented in Figure 4. These results indicate that the volume fraction increases with aging time from $37( \pm 1)$ pct. after 1 hour to $46( \pm 3)$ pct. after 1000 hours. Given the constant precipitate size shown in Figure 3, this suggests that the number density of secondary $\gamma^{\prime}$ precipitates increases during aging. The larger uncertainty associated with the volume fraction measurements after 100 hours may be attributed to variations in the observed volume fractions in regions of the sample at different stages of precipitate splitting. The volume fraction of the tertiary $\gamma^{\prime}$ was observed to decrease throughout aging, although this could not be described quantitatively due to the small precipitate size preventing SEM analysis, and unknown specimen thickness preventing volume fraction measurements by TEM. This dissolution of tertiary 

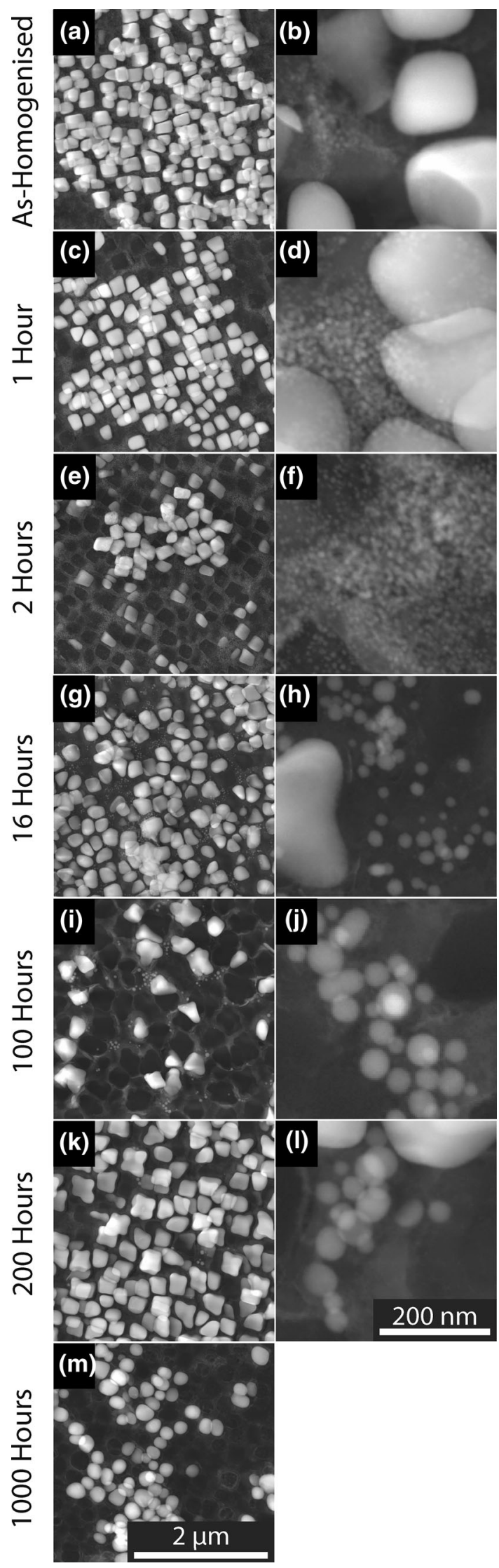

4 Fig. 1- STEM images of extraction replicas of alloy in the as-homogenized state $(a, b)$ and after $1(c, d), 2(e, f), 16(g, h), 100(i, j)$, $200(k, l)$, and $1000(m) \mathrm{h}$ of aging at $1033 \mathrm{~K}\left(760^{\circ} \mathrm{C}\right)$. Secondary $\gamma^{\prime}$ precipitates are shown on the left-hand side (a, c, e, g, i, k, m) and tertiary $\gamma^{\prime}$ precipitates on the right-hand side $(b, d, f, h, j, 1)$. No tertiary precipitates were visible after $1000 \mathrm{~h}$ of aging.

$\gamma^{\prime}$ is driven by Oswald ripening, enabling the growth of the larger secondary $\gamma^{\prime}$ precipitates.

The APT reconstructions showed tertiary $\gamma^{\prime}$ distributions consistent with those obtained by STEM imaging of the carbon replicas, although statistical analysis of the PSDs was limited by the low number of precipitates in each APT needle. An example of one of the APT reconstructions, from the sample aged for 16 hours, is shown in Figure 5. In this figure, each green spot represents a $\mathrm{Cr}$ ion and each blue spot represents an $\mathrm{Al}$ ion. Isosurfaces corresponding to $\mathrm{Cr}$ concentrations of 15 at. pct. have been included to delineate the matrix/precipitate boundaries. A large range of tertiary $\gamma^{\prime}$ sizes can be seen, along with a region bounding a secondary $\gamma^{\prime}$ precipitate in which no tertiary $\gamma^{\prime}$ precipitates are present.

The compositional variation of each phase as a function of aging time is shown in Figure 6. The STEM-EDX data are presented as open markers, with error bars corresponding to the standard deviation of the values obtained. APT data are presented as solid lines between solid markers and the ThermoCalc predictions of the equilibrium compositions are given as dashed lines.

Measurements of the matrix composition, Figure 6(a), indicated that it contained high concentrations of $\mathrm{Cr}$ and $\mathrm{Mo}$, as well as low levels of $\mathrm{Al}$ and $\mathrm{Ti}$, relative to the nominal alloy composition. These results were consistent with the established elemental partitioning behavior between the phases of commercial Ni-based superalloys. ${ }^{[18]}$ There is good agreement between the experimentally determined STEM-EDX and APT data for all elements, with differences typically lying within the range of experimental uncertainty. With increasing aging time, the concentration of each element was observed to be approximately constant and generally corresponded well with the equilibrium concentrations predicted by ThermoCalc. Of the elements present, only the $\mathrm{Cr}$ concentration was consistently different to the ThermoCalc predictions, being underpredicted by $\sim 2$ at. pct.

The variation in elemental concentration with aging time in the secondary $\gamma^{\prime}$ is shown in Figure 6(b). As expected, the $\mathrm{Al}$ and $\mathrm{Ti}$ concentrations are comparatively high compared to the nominal alloy composition, while the $\mathrm{Cr}$ and Mo levels are comparatively low. As with the $\gamma$ matrix composition, there is generally good agreement between the elemental concentrations measured by STEM-EDX and those obtained with APT. However, a notable disparity exists between the Al concentrations measured with the two techniques. This is due to the fact that the $\mathrm{K} \alpha$ emissions from $\mathrm{Al}$ have 

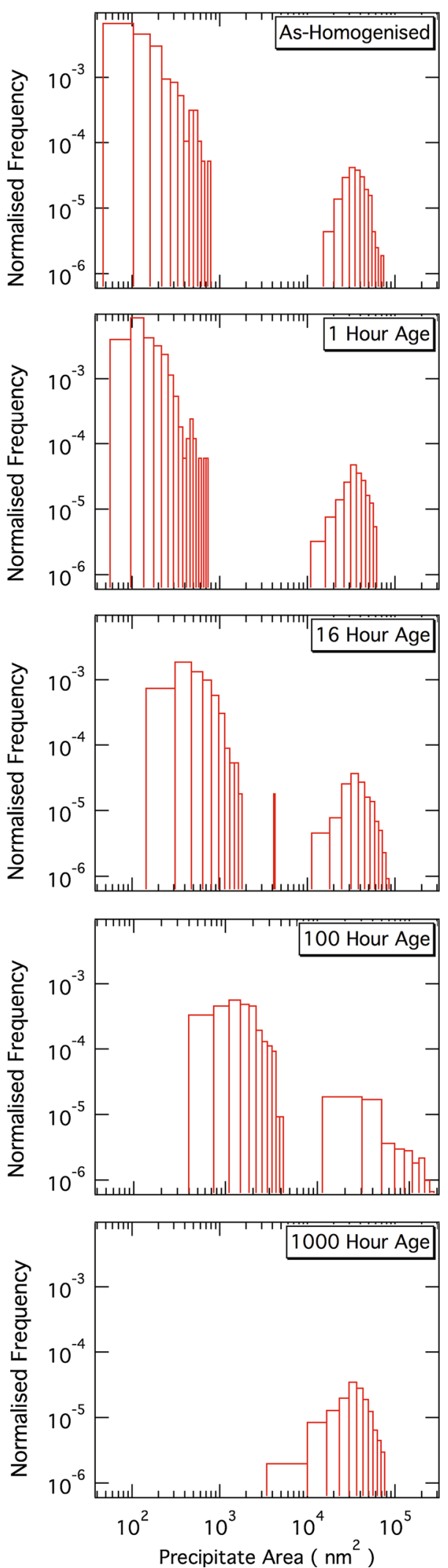

Fig. 2- Particle size distributions (PSDs) of the $\gamma^{\prime}$ precipitates in the as-homogenized state and after aging for $1,16,100$, and $1000 \mathrm{~h}$ at $1033 \mathrm{~K}\left(760^{\circ} \mathrm{C}\right)$ (Color figure online).

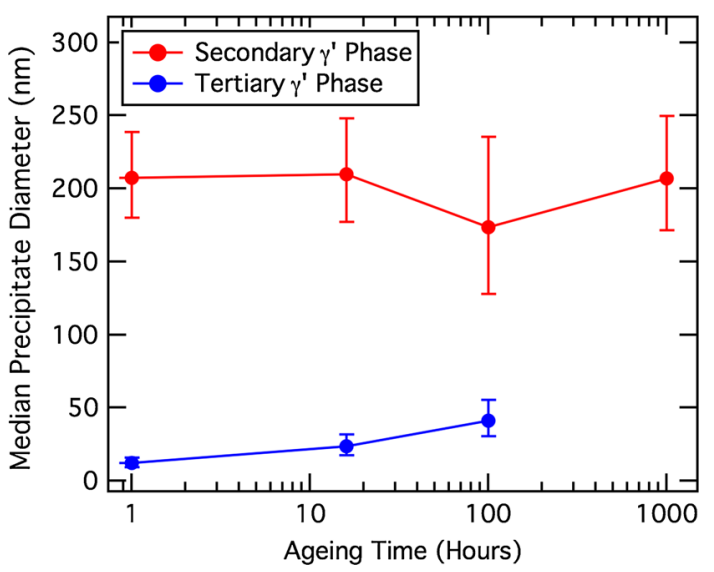

Fig. 3- Mean diameters of the secondary and tertiary $\gamma^{\prime}$ precipitates as a function of aging time at $1033 \mathrm{~K}\left(760^{\circ} \mathrm{C}\right)($ Color figure online).

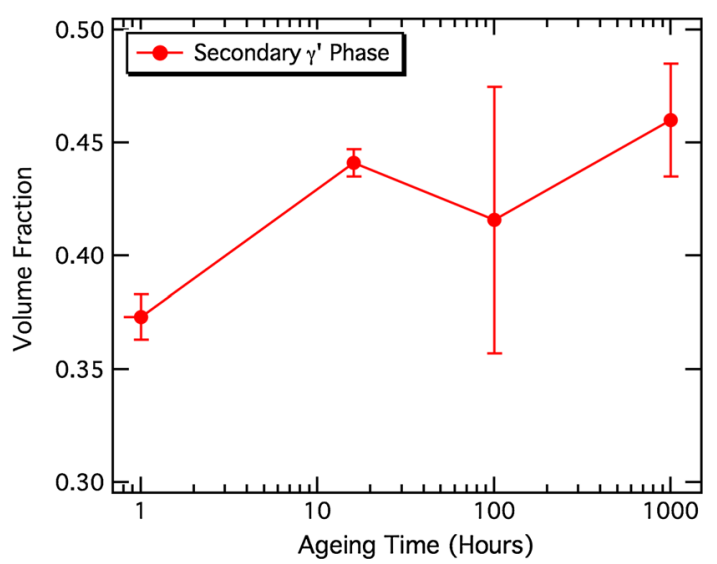

Fig. 4- Volume fraction of the secondary $\gamma^{\prime}$ precipitates as a function of aging time at $1033 \mathrm{~K}\left(760^{\circ} \mathrm{C}\right)$ (Color figure online).

very low energy and are therefore easily absorbed by the sample without being detected during STEM-EDX, resulting in an underestimation of the Al concentration. ${ }^{[19]}$ As a consequence, where the experimental data for Al differed in this way, the APT data were deemed to be more reliable.

Progressive variations in elemental concentrations with aging time in the secondary $\gamma^{\prime}$ phase can be discerned from the data presented in Figure 6(b). The Al APT data suggest that the concentration of this element increases from 11.3 at. pct. after 1 hour of aging to 12.5 at. pct. after 1000 hours. These values bound the equilibrium concentration of $\sim 12$ at. pct. predicted for the $\gamma^{\prime}$ phase by ThermoCalc. The $\mathrm{Cr}$ and $\mathrm{Ti}$ show evidence of a decrease in concentration with increasing aging time, although these changes are small and were not significantly beyond the experimental uncertainty. While the measured $\mathrm{Cr}$ concentration trended towards that predicted by ThermoCalc, the $\mathrm{Ti}$ concentration differed markedly, being approximately 1 to 2 at. pct. below the predicted values. Notably, the concentration 


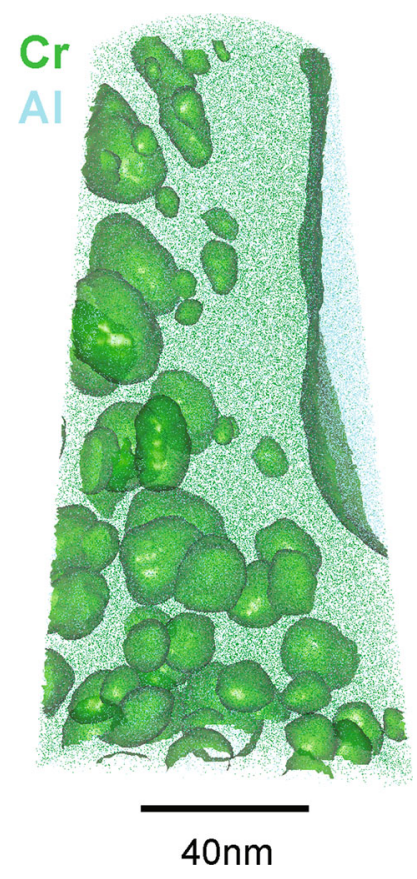

Fig. 5- APT reconstruction of the alloy after $16 \mathrm{~h}$ of aging at $1033 \mathrm{~K}$ $\left(760{ }^{\circ} \mathrm{C}\right)$. Green spots represent the detection of one $\mathrm{Cr}$ ion, while blue spots represent one $\mathrm{Al}$ ion. $\gamma^{\prime}$ precipitates have been highlighted by the addition of an isosurface at 15 at. pct. Cr. One secondary and many tertiary precipitates are visible (Color figure online).

of Mo in the secondary $\gamma^{\prime}$ increased from 0.7 at. pct. after aging for 1 hour to 1.5 at. pct. after 1000 hours. This change in Mo concentration was unexpected as it tended away from the predicted concentration of $\sim 0.1$ at. pct.

Analyses of the elemental concentrations in the tertiary $\gamma^{\prime}$, Figure 6(c), also identified unexpectedly high levels of Mo, which were in excess of 2 at. pct. and varied from 2.9 at. pct. after 1 hour of aging to 2.1 at. pct. after 100 hours of aging from the APT data. Both the $\mathrm{Al}$ and $\mathrm{Ti}$ contents increased slightly on aging to 100 hours, although the $\mathrm{Ti}$ content was markedly lower than that of the secondary $\gamma^{\prime}$. Significant differences were observed between the $\mathrm{Cr}$ concentrations measured by APT and STEM-EDX. The APT data were consistent in the range of 4 to 6 at. pct., while the STEM-EDX data varied from 5 to 14 at. pct. While it may be possible that these discrepancies arose as a result of statistical variations between the precipitates sampled, the effect of retained $\gamma$ within the carbon replica samples cannot be entirely dismissed and would account for the anomalously high Cr levels in the STEM-EDX measurements at 1,2, and 200 hours. With the exception of $\mathrm{Al}$, the equilibrium elemental concentrations predicted by ThermoCalc do not agree well with the experimentally measured values, nor do they appear to be trending toward the predicted values with prolonged time at temperature.

Figures 7(a) and (b) show the proxigrams of the elemental concentrations across the secondary and tertiary $\gamma / \gamma^{\prime}$ interfaces measured by APT of the sample aged for 16 hours. In these figures, all distances are

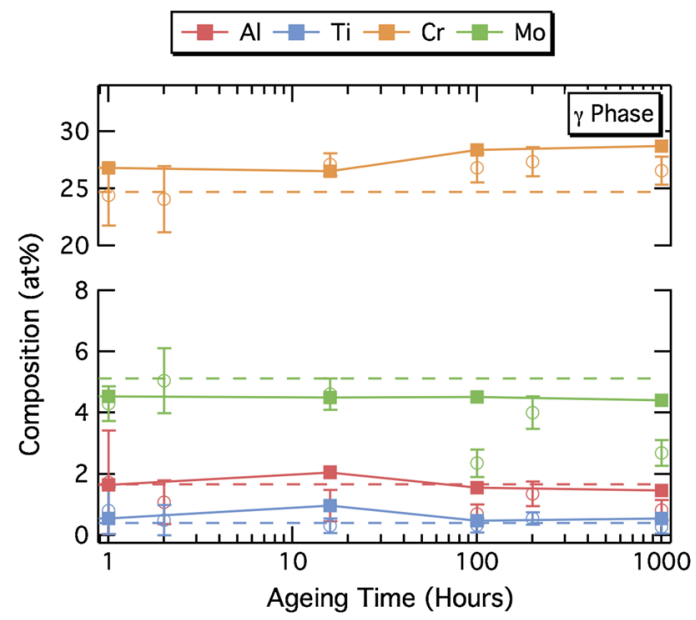

(a)

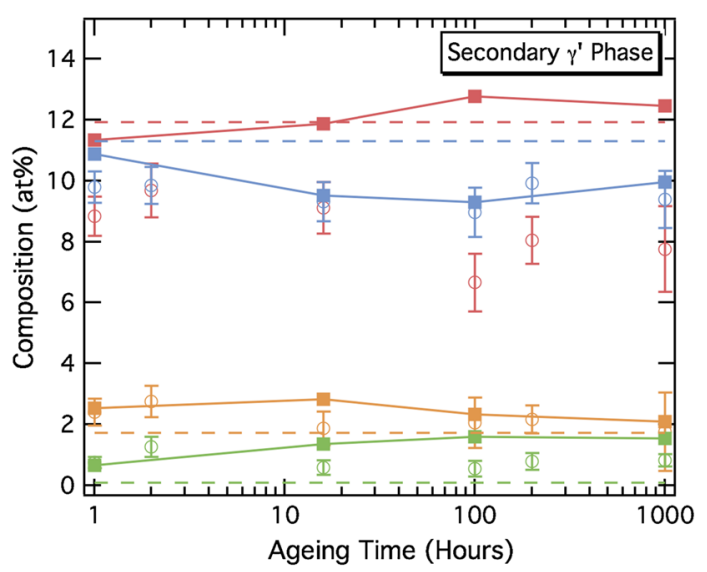

(b)

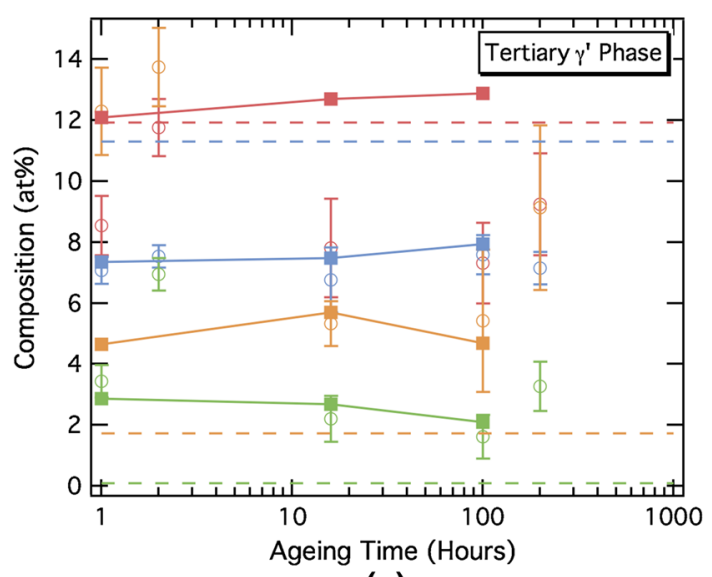

(c)

Fig. 6- Composition of the matrix (a), secondary (b) and tertiary (c) $\gamma^{\prime}$ precipitates as a function of aging time at $1033 \mathrm{~K}\left(760{ }^{\circ} \mathrm{C}\right)$. Experimental APT data are shown as square markers joined by solid lines, while STEM-EDX data are displayed as open markers. Predicted equilibrium phase compositions from ThermoCalc are displayed as dotted lines (Color figure online).

quoted with respect to the 15 at. pct. Cr isosurface. Proxigrams for the other aging times are available in the Supplementary Information. The elemental concentra- 


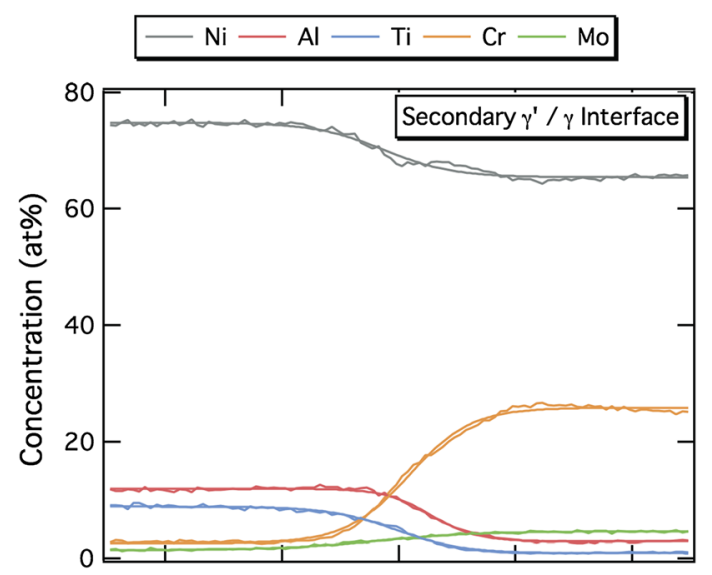

(a)

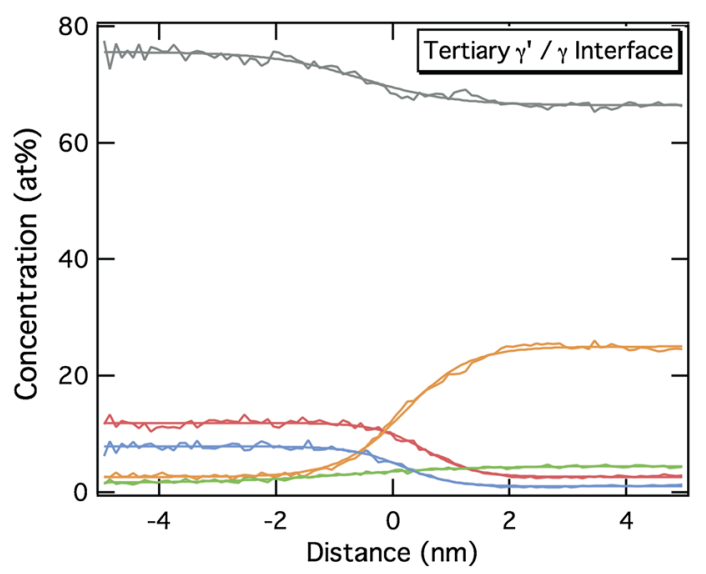

(b)

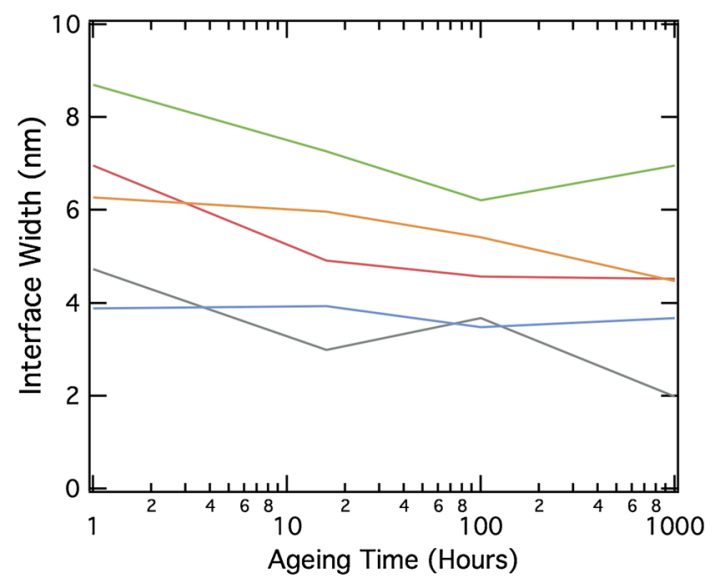

(c)

Fig. 7- Proximity histogram of elemental concentrations across the secondary $\gamma^{\prime} / \gamma$ interface $(a)$ and the tertiary $\gamma^{\prime} / \gamma$ interface $(b)$ for the alloy aged for $16 \mathrm{~h}$. (c) The variation of the secondary $\gamma^{\prime} / \gamma$ interface width as a function of aging time (Color figure online).

tion profiles all showed sigmoidal variations. As with previous reports, an accumulation of nickel was observed $\sim 2 \mathrm{~nm}$ into the $\gamma$ matrix. ${ }^{[20]}$ The quantitative analysis of the secondary $\gamma^{\prime}$ interface width for each element was performed in WaveMetrics Igor Pro and the results are presented in Figure $7(\mathrm{c})$. Values for the interface width for each element were calculated as the distance between 1 pct above and 1 pct below the minimum and maximum compositions, respectively. These data showed a progressive decrease in the width of the interface for all elements with increasing aging time, from which it can be seen that Mo has the largest interface width and $\mathrm{Ni}$ has the smallest.

The lattice parameters of the $\gamma$ and $\gamma^{\prime}$ phases and the associated lattice misfit obtained by neutron diffraction are presented in Figure 8. These results indicate that the lattice parameters and lattice misfit are approximately constant throughout aging, within the experimental uncertainty. This is consistent with the nearly constant APT compositions of the $\gamma$ and $\gamma^{\prime}$ phases, Figure 6. The average measured lattice misfit was determined to be $-0.050 \pm 0.008$ pct. In comparison, the lattice misfit predicted using ThermoCalc was 0.43 pct. The inconsistency of this prediction with the experimental results cannot be attributed to the effect of lattice constraint between the two phases, since the signs of the predicted and measured lattice misfits differ. Similarly, the discrepancy cannot be ascribed to differences between the measured and predicted compositions, as a larger, positive lattice misfit is predicted when using the experimentally determined compositions within ThermoCalc.

\section{DISCUSSION}

\section{A. Precipitate Morphology}

During the early stages of aging at $1033 \mathrm{~K}\left(760^{\circ} \mathrm{C}\right)$, the secondary $\gamma^{\prime}$ size remained approximately constant, while the volume fraction increased by $\sim 7$ pct., Figures 3 and 4. This suggests that this distribution is in a growth phase, leading to an increased number density of precipitates. The apparent absence of coarsening during this period differs from previous studies of precipitate evolution in other superalloys ${ }^{[21-23]}$ and could be a consequence of the low lattice misfit, and associated strain energy, between the $\gamma$ and $\gamma^{\prime}$ phases providing a minimal driving force for this process. A constant lattice misfit has previously been observed in a similar alloy on aging up to 12 hours and linked to a constant secondary $\gamma^{\prime}$ precipitate size. ${ }^{[2]}$

After 100 hours of aging, the secondary $\gamma^{\prime}$ showed evidence of morphological changes, with cuboidal and octodendritic precipitates being observed in the microstructure. In alloys with moderate to high lattice misfits, morphological changes of this type are commonly associated with the magnitude of the lattice misfit, with a progression from spheres to cuboids and finally to octodendrites, in order to minimize the elastic strain energy of the matrix as the precipitates coarsen. ${ }^{[16,17]}$ However, in this alloy, the lattice misfit is low, and therefore the precipitates would be expected to remain spheroidal throughout aging.

The splitting of octodendritic precipitates into smaller spherical or cuboidal precipitates is also driven by a reduction in the overall energy of the system and occurs when the overall elastic strain energy overcomes the 

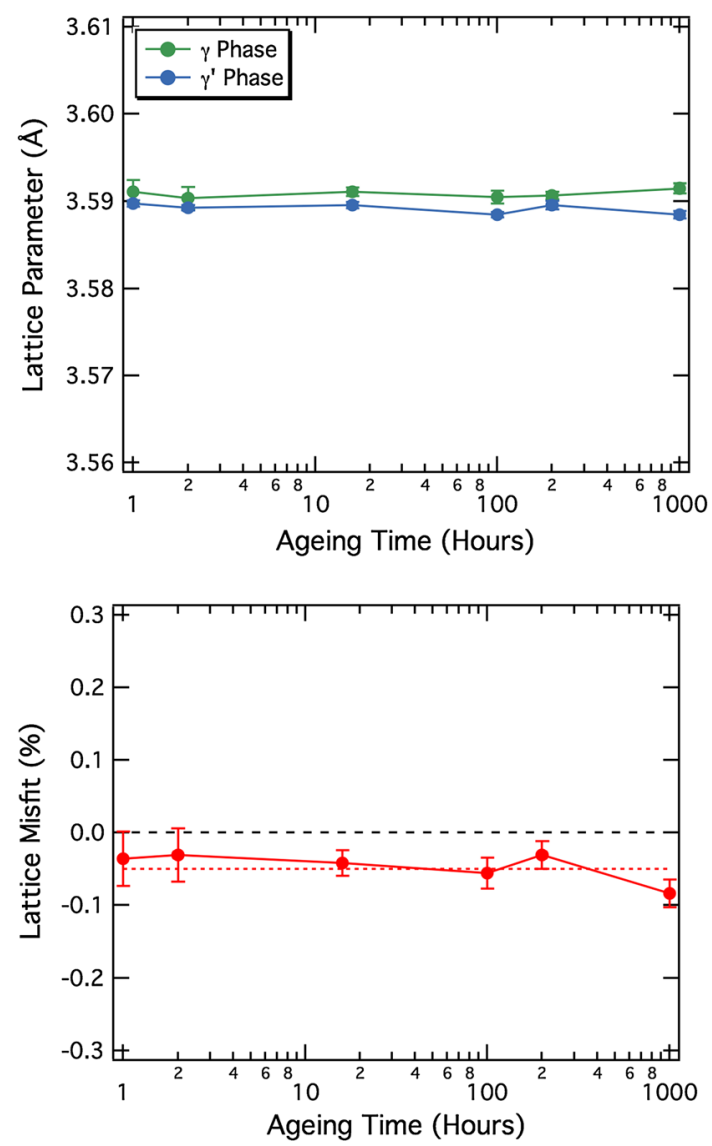

Fig. 8- Variation of the lattice parameter of each phase, and the lattice misfit of the alloy as a function of aging time at $1033 \mathrm{~K}$ $\left(760{ }^{\circ} \mathrm{C}\right)$. The average lattice misfit during aging is shown as a dotted line (Color figure online).

increased interfacial energy of the split precipitates. ${ }^{[24-30]}$ Although splitting is commonly associated with high misfit alloys, ${ }^{[24]}$ it has been observed previously in low misfit alloys such as RR1000 and UCO1. ${ }^{[28,29]}$ The morphological instabilities that can lead to precipitate splitting ${ }^{[31,32]}$ are known to occur in alloys of varying misfit. It must be noted, however, that the mechanism leading to these instabilities differs depending on the magnitude of the lattice misfit. Alloys with low lattice misfits may form precipitates with such morphologies as a result of diffusion-induced interface instabilities. ${ }^{[33,34]}$ In contrast, in alloys with larger misfits, the process is governed almost entirely by the strain energy. ${ }^{31]}$

Evidence of this process was observed in the microstructure after aging for 100 hours, Figure 1(i). Some regions of this sample contained large, octodendritic precipitates indicative of the precursor to splitting, while other regions contained only smaller, spherical/ cuboidal secondary $\gamma^{\prime}$ precipitates, characteristic of splitting having occurred. Splitting does not occur instantaneously across the whole sample, and hence the 100-hour aged sample contained both larger and smaller secondary $\gamma^{\prime}$ precipitates, resulting in a wider particle size distribution. Additionally, the regions with smaller, spherical/cuboidal precipitates exhibited locally lower volume fraction than those containing larger octodendritic precipitates. This accounts for the large uncertainty associated with the volume fraction data from this condition, Figure 4.

In addition, after the onset of splitting, there appeared to be a decrease in the amount of tertiary $\gamma^{\prime}$ visible in the STEM images of the samples. This is consistent with previous reports. ${ }^{[28]}$ However, quantification of the tertiary $\gamma^{\prime}$ volume fraction could not be reliably performed from the analysis of the STEM images acquired due to difficulties in accurately determining the local foil thickness. The splitting phenomenon also serves to explain the reduced size of the secondary $\gamma^{\prime}$ after 1000 hours, with these precipitates having completed the splitting process. Importantly, the morphological changes observed are not consistent with those that would be expected from instabilities governed by fast growth in selected directions due to supersaturation of the matrix phase. ${ }^{[24]}$

The tertiary $\gamma^{\prime}$ precipitates were observed to increase in size during aging, Figure 3, approximately following a $\mathrm{t}^{1 / 3}$ relationship, as would be expected from classical Lifshitz-Slyozov-Wagner (LSW) theory. ${ }^{[35-38]}$ However, using this relationship and extrapolating the coarsening of the tertiary $\gamma^{\prime}$ to 1000 hours, the predicted size would remain below that of the secondary $\gamma^{\prime}$ precipitates. This confirms that the absence of tertiary $\gamma^{\prime}$ after 1000 hours of aging is due to resolution of the precipitates, as opposed to coarsening to a size sufficient to merge with that of the secondary $\gamma^{\prime}$.

\section{B. Precipitate Composition}

In the as-homogenized condition and in the majority of the aged samples, the model alloy exhibited a bimodal size distribution of secondary and tertiary precipitates. Both the secondary and tertiary $\gamma^{\prime}$ form on cooling from the homogenization temperature, with the secondary $\gamma^{\prime}$ forming before the tertiary $\gamma^{\prime}$, at higher temperature. ${ }^{[39,40]}$ The higher elemental mobility during the formation of the secondary $\gamma^{\prime}$ produces larger precipitates and facilitates the movement of Mo and $\mathrm{Cr}$ out of the $\gamma^{\prime}$ and into the matrix phase in which they preferentially reside. In contrast, as a result of the lower temperature and therefore reduced diffusion during the formation of the tertiary $\gamma^{\prime}$, this distribution is generally enriched in those elements that partition to the $\gamma$ phase during secondary formation, resulting in a composition further from the equilibrium predicted value. ${ }^{[41]}$ The Mo content of the $\gamma^{\prime}$ precipitate phase has been shown to decrease with increasing aging temperature, in agreement with this principle. ${ }^{[42]}$

During aging of the alloy, relatively modest changes in the composition of the phases present were observed, Figure 6. Most notably, the tertiary $\gamma^{\prime}$ phase contained markedly higher concentrations of $\mathrm{Mo}$ and $\mathrm{Cr}$ and a lower concentration of Ti than the secondary $\gamma^{\prime}$ precipitates. While the Mo and $\mathrm{Al}$ concentrations in the two precipitate size distributions appear to be converging with increasing aging time (as seen in Reference 43), it is not clear that this is true of the $\mathrm{Cr}$ and $\mathrm{Ti}$ concentra- 
tions. The elevated Mo concentrations observed in the $\gamma^{\prime}$ precipitates are consistent with data reported by Jou et al. ${ }^{44]}$ on IN100. Similarly, a significant Mo concentration in the secondary $\gamma^{\prime}$ phase has also been reported by Loomis et al..$^{[45]}$ in an investigation of similar model alloys to those studied here. However, a previous study comparing experimental compositions from APT to equilibrium predictions by ThermoCalc did not find the Mo content in the $\gamma^{\prime}$ to be as high as the present study. ${ }^{[46]}$

It has been shown previously that the composition of $\gamma^{\prime}$ precipitates is dependent on size within the range of $5 \mathrm{~nm}$ to $3 \mu \mathrm{m} \cdot{ }^{[25]}$ In the present study, no link was found between the size of the $\gamma^{\prime}$ precipitates within each size distribution and the composition. ${ }^{[47]}$ However, the range of precipitate sizes within each distribution in the current study is small and, therefore, a wider range of precipitate sizes may have revealed compositional variations.

The concentration profile widths in Figure 7(c) decreased continuously during aging for all elements. This is consistent with the studies of Ni-Al, ${ }^{[48]} \mathrm{Ni}-\mathrm{Al}$ $\mathrm{Cr},{ }^{[49]}$ and $\mathrm{Ni}-\mathrm{Al}-\mathrm{Cr}-\mathrm{Ta}^{[20]}$ alloys, which showed rapid decreases in the interface widths in the early stages of aging and lower rates of decrease with prolonged time at temperature, as the precipitates entered the coarsening regime. However, it is noted that the opposite behavior of increasing interfacial width has been reported during the aging of secondary $\gamma^{\prime}$ precipitates in the commercial superalloy Rene $88 \mathrm{DT} .{ }^{43,50]}$ This suggests that a number of factors may influence interfacial width. For example, it has been shown that a sharper interface results from slower cooling rates in AM1. ${ }^{[4]}$ The relative magnitudes of the interfacial width differ for each element, with the faster diffusing species, Al and Ti, exhibiting narrower interfaces than those that diffuse more slowly. This is particularly notable for Mo, which displays the widest interface despite having the smallest difference in concentration between the $\gamma$ and $\gamma^{\prime}$ phases. Theoretical descriptions exist that account for the finite width of the $\gamma / \gamma^{\prime}$ interface, as observed in this study. These include the original work by Cahn and Hilliard ${ }^{51]}$ that utilized gradient energy coefficients to account for the free energy of regions of non-constant composition, and the more recent trans-interface chemical diffusion model by Ardell ${ }^{[52,53]}$ where the kinetics are controlled by diffusion through, rather than to, the $\gamma / \gamma^{\prime}$ interface.

Composition has previously been linked to precipitate morphology in a study on the low misfit alloy RR1000, where it was shown that restricted elemental diffusion resulted in cyclic coarsening and splitting of the secondary $\gamma^{\prime}{ }^{[29]}$ It was shown that the Al concentration of the $\gamma^{\prime}$ phase generally increased on aging at $1073 \mathrm{~K}$ $\left(800{ }^{\circ} \mathrm{C}\right)$, reaching a maximum immediately following splitting. In contrast, the concentration of Ti remained approximately constant during aging but exhibited a local minimum after splitting. The overall trends in the composition of $\mathrm{Al}$ and $\mathrm{Ti}$ in the alloy here studied are not inconsistent with these results, although sampling at more regular intervals would be required to determine the local changes associated with splitting.

\section{Lattice Misfit}

The difference between the secondary and tertiary $\gamma^{\prime}$ compositions would be expected to result in differing lattice parameters for these distributions and, consequently differing lattice misfits. However, the broad intrinsic peak width and comparatively low volume fraction of the tertiary $\gamma^{\prime}$ phase prohibited separation of the contributions of this distribution to the superlattice reflections in the neutron diffraction data, which were therefore dominated by the secondary $\gamma^{\prime} .^{[54]}$

\section{Consequences for Mechanical Properties}

The differences between the measured compositions of the $\gamma^{\prime}$ precipitates and those predicted by ThermoCalc have implications for the estimation of alloy strength using empirical relations. ${ }^{[3,55,56]}$ Specifically, the high Mo and low $\mathrm{Ti}$ concentrations will affect multiple mechanisms of alloy strengthening concurrently, including solid solution, coherency, and order strengthening. Consequently, the contribution from each strengthening mechanism will vary between the secondary and tertiary $\gamma^{\prime}$ populations as a result of their different compositions. Therefore, relationships describing the properties of superalloys may require modification to accommodate the compositional differences between the $\gamma^{\prime}$ populations, to further improve their fidelity.

\section{CONCLUSIONS}

The microstructure and phase composition of a model polycrystalline Ni-based superalloy have been characterized using STEM-EDX and APT, following aging at $1033 \mathrm{~K}\left(760^{\circ} \mathrm{C}\right)$ for durations of up to 1000 hours. Microstructural analysis revealed that the size of the secondary $\gamma^{\prime}$ precipitates remained approximately constant during the early stages of aging, but exhibited the morphological instabilities associated with precipitate splitting following longer duration exposures. In contrast, when the tertiary $\gamma^{\prime}$ precipitates were present in the microstructure, they were observed to coarsen in line with LSW theory. The experimentally determined phase compositions were compared to equilibrium predictions made using ThermoCalc. The composition of the $\gamma$ phase was seen to remain approximately constant during aging, with elemental concentrations similar to the equilibrium phase composition predicted by ThermoCalc. Compositional analysis of the secondary and tertiary $\gamma^{\prime}$ precipitates revealed small changes in elemental concentration with increasing aging time. Notably, higher Mo and lower Ti concentrations were observed than those predicted using ThermoCalc. These results are believed to have implications for models describing alloy properties, which currently employ thermodynamic equilibrium predictions of phase composition. 


\section{ACKNOWLEDGMENTS}

The authors wish to acknowledge Mrs. S. Rhodes, Dr. H.T. Pang, Dr. D.M. Collins, and Dr. O.M.D.M. Messé for their assistance with the experiments performed. Funding was provided by the EPSRC/RollsRoyce Strategic Partnership under EP/M005607/1 and EP/H022309/1. The Oxford Atom Probe facility was funded by the EPSRC under EP/M022803/1. Neutron diffraction beam time was supported through the Canadian Neutron Beam Centre under Experiment number 1258 .

\section{OPEN ACCESS}

This article is distributed under the terms of the Creative Commons Attribution 4.0 International License (http://creativecommons.org/licenses/by/4.0/), which permits unrestricted use, distribution, and reproduction in any medium, provided you give appropriate credit to the original author(s) and the source, provide a link to the Creative Commons license, and indicate if changes were made.

\section{ELECTRONIC SUPPLEMENTARY MATERIAL}

The online version of this article (doi:10.1007/s11661017-4336-y) contains supplementary material, which is available to authorized users.

\section{REFERENCES}

1. R.F. Decker: Steel Strengthening Mechanisms Symposium, 1969, pp. 1-24.

2. R.C. Reed: The Superalloys, 1st ed., Cambridge University Press, Cambridge, 2006, p. 81.

3. D.M. Collins and H.J. Stone: Int. J. Plast., 2014, vol. 54, pp. $96-112$.

4. D. Locq, A. Coujou, P. Caron, S. Raujol, F. Pettinari-Sturmel, and N. Clemént: Tenth International Symposium on Superalloys, 2004, pp. 179-87.

5. R.A. Stevens and P.E.J. Flewitt: Mater. Sci. Eng., 1979, vol. 37, pp. 237-47.

6. J. Coakley, H. Basoalto, and D. Dye: Acta Mater., 2010, vol. 58, pp. 4019-28.

7. H. Basoalto and M. Anderson: Acta Mater, 2016, vol. 117, pp. $122-34$

8. J. Kundin, L. Mushongera, T. Goehler, and H. Emmerich: Acta Mater, 2012, vol. 60, pp. 3758-72.

9. S. Olive, U. Grafe, and I. Steinbach: Comput. Mater. Sci., 1996, vol. 7, pp. 94-97.

10. M.C. Hardy, B. Zirbel, G. Shen, and R. Shankar: Tenth International Symposium on Superalloys, 2004, pp. 83-90.

11. R.C. Ecob, R.A. Ricks, and A.J. Porter: Scr. Metall., 1982, vol. 16, pp. 1085-90.

12. V. Randle, I. Barker, and B. Ralph: J. Electr. Microsc. Tech., 1989, vol. 13 , pp. 51-65.

13. C.A. Schneider, W.S. Rasband, and K.W. Eliceiri: Nat. Methods, 2012, vol. 9, pp. 671-75.

14. D. Freedman and P. Diaconis: Z. Fur Wahrscheinlichkeitstheorie Und Verw. Geb., 1981, vol. 57, pp. 453-76.

15. J.B. Nelson and D.P. Riley: Proc. Phys. Soc. Lond., 1945, vol. 57, pp. $160-77$.
16. R.A. Ricks, A.J. Porter, and R.C. Ecob: Acta Metall., 1983, vol. 31, pp. $43-53$.

17. A. Royer and P. Bastie, Eighth International Symposium on Superalloys, 1996, pp. 222-28.

18. A.K. Jena and M.C. Chaturvedi: J. Mater. Sci., 1984, vol. 19, pp. 3121-39.

19. A.D. Westwood, J.R. Michael, and M.R. Notis: J. Microsc., 2011, vol. 167 , pp. 287-302.

20. C. Booth-Morrison, R.D. Noebe, and D.N. Seidman: Acta Mater, 2009, vol. 57, pp. 909-20.

21. T.P. Gabb, J. Gayda, D.F. Johnson, R.A. Mackay, R.B. Rogers, C.K. Sudbrack, A. Garg, I.E. Locci, S.L. Semiatin, and E. Kang: Report No. 218936, NASA, February 2016.

22. S. Zhao, J. Dong, X. Xie, G.D. Smith, and S.J. Patel: Tenth International Symposium on Superalloys, 2004, pp. 63-72.

23. A. Ges, O. Fornaro, and H. Palacio: J. Mater. Sci., vol. 32, pp. 3687-91.

24. Y.S. Yoo: Scr. Mater, 2005, vol. 53, pp. 81-85.

25. Y.Q. Chen, E. Francis, J. Robson, M. Preuss, and S.J. Haigh: Acta Mater., 2015, vol. 85, pp. 199-206.

26. A.C. Lund and P.W. Voorhees: Acta Mater, 2002, vol. 50, pp. 2085-98.

27. R.J. Mitchell, M. Preuss, M.C. Hardy, and S. Tin: Mater. Sci. Eng. A, 2006, vol. 423, pp. 282-91.

28. R.J. Mitchell and M. Preuss: Metall. Mater. Trans. A, 2007, vol. 38A, pp. 615-27.

29. Y. Chen, R.P. Babu, T.J.A. Slater, M. Bai, R. Mitchell, O. Ciuca, M. Preuss, and S.J. Haigh: Acta Mater., 2016, vol. 110, pp. 295-305.

30. M. Doi and T Miyazaki: Sixth International Symposium on Superalloys, 1988, pp. 663-72.

31. Y.S. Yoo, D.Y. Yoon, and M.F. Henry: Metals Mater, 1995, vol. 1, pp. 47-61.

32. M.J. Kaufman, P.W. Voorhees, W.C. Johnson, and F.S. Biancaniello: Metall. Trans. A, 1989, vol. 20A, pp. 2171-75.

33. M.F. Henry, Y.S. Yoo, D.Y. Yoon, and J. Choi: Metall. Trans. A, 1993, vol. 24A, pp. 1733-43.

34. W.W. Mullins and R.F. Sekerka: J. Appl. Phys., 1963, vol. 34, pp. 323-29.

35. M. Hillert, O. Hunderi, N. Ryum, and T.O. Sætre: Scr. Metall., 1989, vol. 23, pp. 1979-81.

36. C. Wagner: Z. Elektrochem., 1961, vol. 65, pp. 581-91.

37. I.M. Lifshitz and V.V. Slyozov: J. Phys. Chem. Solids, 1961, vol. 19, pp. $35-50$.

38. L.C. Brown: Acta Metall., 1989, vol. 37, pp. 71-77.

39. P.M. Sarosi, B. Wang, J.P. Simmons, Y. Wang, and M.J. Mills: Scr. Mater, 2007, vol. 57, pp. 767-70.

40. Y.H. Wen, J.P. Simmons, C. Shen, C. Woodward, and Y. Wang: Acta Mater, 2003, vol. 51, pp. 1123-32.

41. S.S. Babu, M.K. Miller, J.M. Vitek, and S.A. David: Acta Mater., 2001, vol. 49, pp. 4149-60.

42. E.H. Van der Molen, J.M. Oblak, and O.H. Kriege: Metall. Trans., 1971, vol. 2, pp. 1627-33.

43. J.Y. Hwang, R. Banerjee, J. Tiley, R. Srinivasan, G.B. Viswanathan, and H.L. Fraser: Metall. Mater. Trans. A, 2009, vol. 40, pp. 24-35.

44. H.J. Jou, P. Voorhees, and G.B. Olson, Tenth International Symposium on Superalloys, 2004, pp. 877-86.

45. W.T. Loomis, J.W. Freeman, and D.L. Sponseller: Metall. Trans., 1972, vol. 3, pp. 989-1000.

46. X.P. Tan, D. Mangelinck, C. Perrin-Pellegrino, L. Rougier, C.A. Gandin, A. Jacot, D. Ponsen, and V. Jaquet: JalcomJ. Alloys Compd., 2014, vol. 611, pp. 389-94.

47. D.M. Collins, L. Yan, E.A. Marquis, L.D. Connor, J.J. Ciardiello, A.D. Evans, and H.J. Stone: Acta Mater, vol. 61, pp. 7791-04.

48. E.Y. Plotnikov, Z. Mao, R.D. Noebe, and D.N. Seidman: Scr. Mater., 2014, vol. 70, pp. 51-54.

49. S. Meher, S. Nag, J. Tiley, A. Goel, and R. Banerjee: Acta Mater, 2013, vol. 61, pp. 4266-76.

50. J.Y. Hwang, S. Nag, A.R.P. Singh, G.B. Viswanathan, J. Tiley, R. Srinivasan, H.L. Fraser, and R. Banerjee: Microsc. Microanal., 2009 , vol. 15 , pp. $268-69$.

51. J.W. Cahn and J.E. Hilliard: J. Chem. Phys., 1958, vol. 28, pp. $258-67$ 
52. A. Ardell and V. Ozolins: Nat. Mater., 2005, vol. 4, pp. 309-316.

53. A. Ardell: Scr. Mater, 2012, vol. 66, pp. 423-26.

54. L.D. Connor, H.J. Stone, D.M. Collins, M. Preuss, M.C. Hardy, and C.M.F. Rae: Metall. Mater. Trans. A, 2014, vol. 45A, pp. 2436-44.
55. R.W. Kozar, A. Suzuki, W.W. Milligan, J.J. Schirra, M.F. Savage, and T.M. Pollock: Metall. Mater. Trans. A, 2009, vol. 40, pp. $1588-1603$.

56. E.I. Galindo-Nava, L.D. Connor, and C.M.F. Rae: Acta Mater, 2015, vol. 98, pp. 377-90. 